\title{
Influence of Fault Plane Heterogeneity on the Seismic Behavior in the Southern Kurile Islands Arc
}

\author{
SUSAN Y. SCHWARTZ \\ Charles F. Richter Seismological Laboratory, University of California, Santa Cruz
}

JAMES W. DEWEY

U.S. Geological Survey, Denver, Colorado

THORNE LAY

Department of Geological Sciences, University of Michigan, Ann Arbor

\begin{abstract}
The seismic behavior in the southern Kurile Islands Arc is strongly influenced by spatial heterogeneity in the mechanical properties of the plate interface. Maps showing sites of maximum seismic moment release for the great underthrusting earthquakes of 1958, 1963,1969, and 1973 provide a first-order image of the major regions of enhanced strength, or asperities. Hypocenters of these and an additional 83 smaller earthquakes with $m_{b} \geq 5.3$ and known underthrusting mechanisms were recomputed using the method of joint hypocenter determination in order to assess better the influence that the strength distribution exerts on the interplate seismicity patterns. Nearly all of the smallermagnitude earthquakes locate outside of the principal asperities of the great earthquakes. This observation is consistent with substantial release of accumulated strain energy in asperity regions during the great earthquakes and a redistribution of stress in adjacent areas following their rupture. An along-dip, depth dependent component of strength heterogeneity appears to influence the seismicity patterns. The asperities of the 1958 and 1973 great earthquakes and hypocenters of most of the $M_{s} \geq$ 7 earthquakes occur near the downdip edge of the $100-\mathrm{km}$-wide seismically active plate interface. This would be expected if shear resistance on the interface increases monotonically with lithostatic pressure up to the brittle-ductile or stick slip-stable slip transition that defines the base of the seismogenic zone. The asperities of the 1963 and 1969 earthquakes, however, appear to be located well above the downdip edge of the coupled plate interface. The occurrence of large asperities in middepth ranges of the seismogenic interface suggests the influence of along-dip changes in other parameters, besides lithostatic pressure, that control shear resistance. Along-strike segmentation of the Kurile Islands thrust zone may be a consequence of along-strike alternation in the location of the largest asperities between the deep interface and the midinterface.
\end{abstract}

\section{INTRODUCTION}

Spatiotemporal patterns of seismicity associated with large earthquakes have been extensively studied in attempts to develop methodologies for earthquake prediction. While these studies have revealed substantial complexity and regional variations in seismic behavior, they have also led to the recognition that one physical mechanism may be responsible for this variability. Kanamori [1981] proposed that a wide range in observed seismic behavior can be explained with a single model involving spatial heterogeneity in the mechanical properties of the fault plane. In this model a fault contact consists of patches having different failure strengths; the strongest regions are referred to as asperities and rupture in the largest earthquakes. The high stress drop involved in rupture of an asperity would imply that a long time would be required to restress the patch to a level that exceeds its failure strength. The weaker portions of the fault plane fail more frequently; they may slip during the largest earthquakes with smaller displacements than at the asperities, they may rupture themselves in smaller earthquakes, or they may slip aseismically. The specific distribution of failure

Copyright 1989 by the American Geophysical Union.

Paper number 89JB00043. 0148-0227/89/89JB-00043\$05.00 strengths along the fault contact therefore controls the resulting space-time seismicity patterns. Since major loci of seismic slip and associated strength heterogeneity can now be determined within the rupture zones of large earthquakes from the inversion of body wave [e.g., Kikuchi and Fukao, 1987; Schwartz and Ruff, 1987; Boyd and Nabelek, 1988; Mendoza and Hartzell, 1988a], surface wave [e.g., Mori and Shimazaki, 1985], and strong ground motion [e.g., Olson and Apsel, 1982; Hartzell and Heaton, 1983; Archuleta, 1984] observations, the influence that the primary strength heterogeneity exerts on regional seismic behavior can be assessed.

For several large North American continental earthquakes, Hartzell and Heaton [1986] and Mendoza and Hartzell $[1988 b]$ have examined the relationship between the distribution of aftershock hypocenters and the pattern of the main shock coseismic displacement estimated from the inversion of strong ground motion and teleseismic records. In these studies, aftershock hypocenters were conspicuously absent from regions where the main shock slip was large and instead tended to cluster near the edges of slip maxima. Choy and Dewey [1988] analyzed broadband $P$ wave velocity and displacement records to determine the dynamic source parameters of the March 3, 1985, Chilean underthrusting earthquake. The area that they identified as radiating most of 
the seismic energy (main shock asperity) was also devoid of aftershock hypocenters. Although these observations are consistent with the asperity model, the contrary assumption is sometimes made when aftershock locations are the only data available on fault plane heterogeneity. The aftershocks are then sometimes assumed to emanate from the main shock asperities. Moreover, it is conceivable that an asperity could continue to "chatter" after a large earthquake, if, for example, the asperity were being restressed by aseismic slip occurring on the fault plane surrounding the asperity. Further documentation of the relationship between aftershock activity and main shock asperities is important for the accurate estimation of regional earthquake hazard.

A primary objective of this paper is to evaluate the influence exerted by heterogeneity of fault plane strength on interplate seismicity patterns along the entire southern Kurile Islands Arc. This arc experienced four great earthquakes in a recent 15 -year period, occurring on November 6 , $1958\left(M_{w}=8.3\right)$, October $13,1963\left(M_{w^{\prime}}=8.5\right)$, August 11 , $1969\left(M_{w},=8.2\right)$, and June 17, $1973\left(M_{\mathrm{w}},=7.8\right)$. The overlapping aftershock zones of the four earthquakes span a $700-\mathrm{km}$-long segment of the thrust interface between the subducting Pacific plate and the overriding Eurasian plate (Figure 1). Our point of departure is the paper of Schwartz and Ruff [1987], which defined the dominant asperities of the four great earthquakes with respect to the epicenters of these events. In this paper we concentrate on locating the asperities within the seismogenic thrust interface, as the interface is defined by other underthrusting earthquakes. We then examine how the accumulation and release of strain at the asperities of the four great southern Kurile Islands earthquakes influence the distribution of smaller earthquakes on the plate interface. Because the great earthquakes occurred in the early part of the time period for which accurate hypocenters can be computed, we are particularly concerned with the effects of their asperity rupture on the seismicity of the plate interface following the great earthquakes.

Our primary data are hypocenters of known underthrusting earthquakes, relocated using travel time station corrections and weighting functions computed by the method of joint hypocenter determination (JHD). The use of station corrections minimizes location errors of hypocenters relative to each other that result from different hypocenters being located by different configurations of seismographic stations, each with a distinct network bias. The relocated hypocenters should therefore (1) enable more reliable definition of the dimensions of the seismically active thrust interface in the southern Kurile Islands Arc, (2) allow more confident positioning of the great earthquake asperities within the seismically active interface, and (3) permit a more definitive test of the tendency for earthquake aftershocks to be concentrated outside of the main shock asperities.

Although it is difficult to estimate the systematic bias of the group of our epicenters as a whole that might arise due to velocity anomalies associated with the subducted Pacific plate, we think that such bias is substantially less than the 40- to $50-\mathrm{km}$ biases that result from downgoing slabs in some subduction zones, such as in the central Aleutians [Engdahl et al., 1982]. We have, moreover, attempted to obtain improved estimates of absolute focal depth by constraining the depths of calibration events and other well-recorded earthquakes to values determined by waveform modeling.
The improved focal depths permit us to make an approximate estimate of the maximum depth extent of the seismically active thrust interface in the southern Kurile Islands Arc.

\section{Data Analysis}

\section{Earthquake Relocations}

All earthquakes with reliable underthrusting mechanisms that occurred since 1963 between $42^{\circ}$ and $46^{\circ} \mathrm{N}$ and $145^{\circ}$ and $152^{\circ} \mathrm{E}$ plus events with $M_{s} \geq 7$ in the same region between 1948 and 1963 have been relocated using the method of joint hypocenter determination (JHD) described by Dewey [1972]. Focal mechanism solutions determined by Stauder and Mualchin [1976] for events between 1963 and 1973, Harvard centroid moment tensor solutions for events between 1977 and 1986 (Dziewonski et al. [1983, 1987a, b, c, 1988a,b] and earthquake data reports of the U.S. Geological Survey) and mechanisms compiled by Schwartz and Ruff [1987] for the remaining years were examined; all dip-slip earthquakes with reported depths less than $100 \mathrm{~km}$ and a shallow $\left(<45^{\circ}\right)$ northwesterly dipping nodal plane were classified as interplate thrust events and included in our analysis. A total of 87 earthquake locations were recomputed.

The procedure in which we use JHD involves three general steps. The first step is the subdivision of the southern Kurile Islands Arc into four overlapping geographic quadrangles (Figure 1) and the determination, for each quadrangle, of calibration events whose epicenters (but not focal depths) are located with respect to each other using only teleseismic data. The second step is the use of JHD to locate the epicenters and focal depths of up to 14 widely recorded events in each quadrangle with respect to the calibration events. Arrival time data from all distance ranges are now used. Besides producing hypocenters of the events, the second step computes station corrections for the approximately 100 stations used in locating the events, and estimates of the variance of arrival time residuals for regional, near-teleseismic, and far-teleseismic phase types used in the computation. The third step is the use of JHD-computed station corrections and variances in a single event location program to calculate, for all events in each quadrangle, hypocenters, $90 \%$ confidence ellipses on the epicentral coordinates, and $90 \%$ confidence ellipsoids on the hypocentral coordinates. The hypocenters plotted in the figures and listed in Table 1 are those produced in the third step; the quality ratings assigned to the hypocenters are based on the sizes of the epicenter confidence ellipses and hypocenter confidence ellipsoids (Table 1 ).

The first two steps of the location procedure are an attempt to balance our need for high relative precision of epicenters along the entire $700-\mathrm{km}$ arc segment with our needs to estimate focal depths of the earthquakes and to maximize relative precision in smaller sections of the arc. The JHD station corrections account for the source to receiver travel time anomalies that are common to the ray paths from all earthquakes to a given station. We assume, for a given set of earthquakes distributed along the arc, that source-receiver anomalies are more likely to be constant for distant stations than for nearby stations, because the difference in the ray paths due to changing event locations is a smaller proportion of the total ray paths for the distant stations. Therefore, to maximize relative location accuracy 

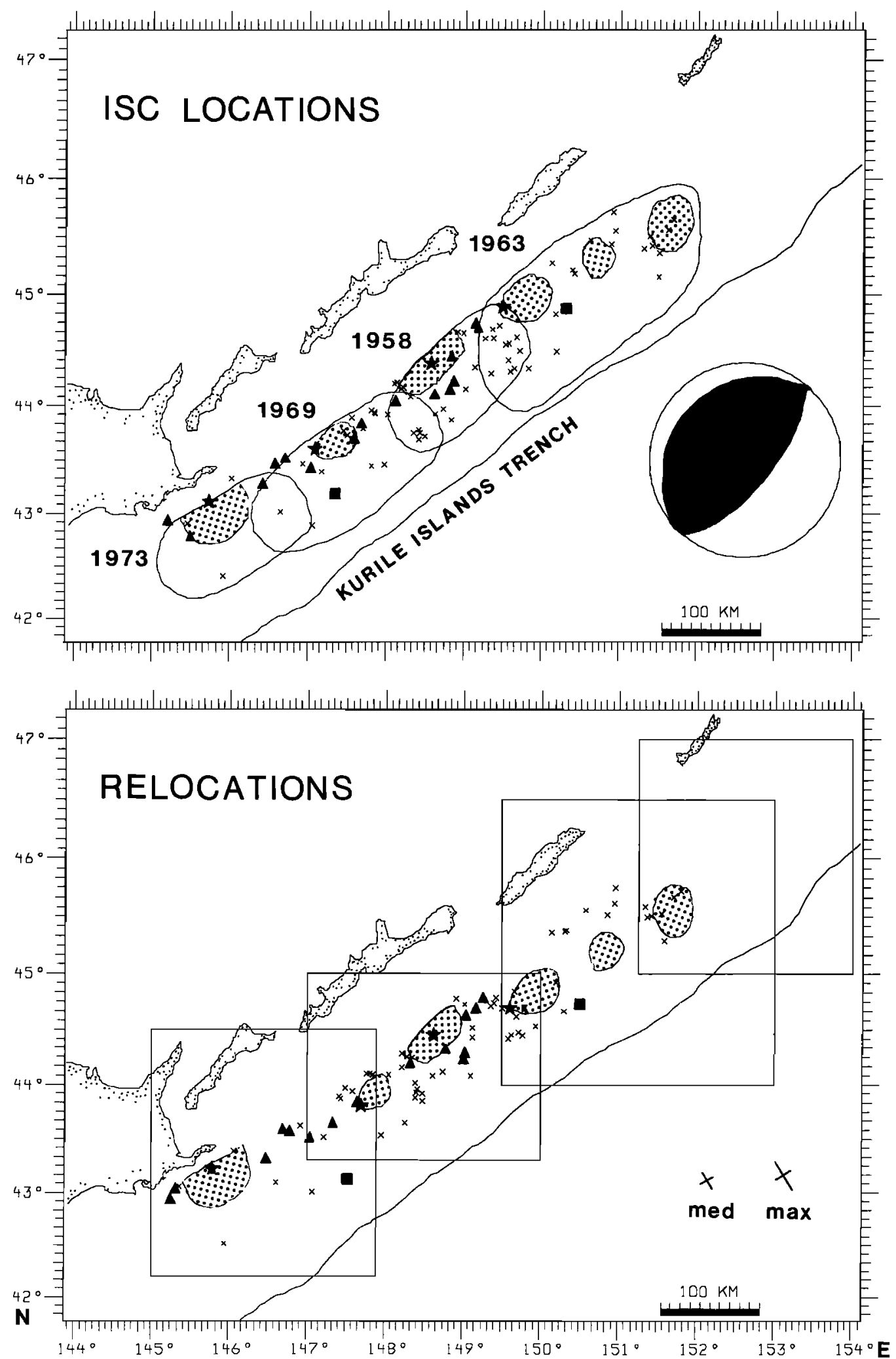

Fig. 1. ISC and relocated epicenters of 84 underthrusting events in the southern Kurile Islands Arc. The great earthquake epicenters are indicated by the stars, and their asperity regions from $S c h w a r t z$ and $R$ uff [1987] are patterned and positioned relative to their ISC or relocated epicenters. Earthquakes with $M_{s} \geq 7$ are shown with solid symbols where the boxes indicate the anomalous tsunamigenic events. The regions outlined in the top panel represent the 3-day aftershock areas of the great earthquakes as defined by routinely cataloged data. The boxes in the bottom panel indicate the four quadrangles used in the relocation procedure. "Max" and "med" show the principal axes of the confidence ellipses corresponding to epicenters of the least and median precision. The focal mechanism shown is a lower hemisphere projection with compressional quadrants shaded and is representative of the 84 events. 
TABLE 1. Kurile Islands Relocated Earthquake Hypocenters

\begin{tabular}{|c|c|c|c|c|c|c|c|c|c|}
\hline Date & $\begin{array}{c}\text { Time, } \\
\text { UT }\end{array}$ & $\underset{{ }^{\circ} \mathrm{N}}{\text { Latitude, }}$ & $\underset{{ }^{\circ} \mathrm{E}}{\text { Longitude, }}$ & $\begin{array}{c}\text { Depth, } \\
\text { km }\end{array}$ & $M_{s}$ & $\begin{array}{l}\text { Strike, } \\
\text { deg }\end{array}$ & $\begin{array}{l}\text { Dip, } \\
\text { deg }\end{array}$ & $\begin{array}{c}\text { Rake, } \\
\text { deg }\end{array}$ & QU† \\
\hline Sept. 10, 1948 & $1348: 34.0$ & 43.65 & 147.34 & 38.5 & 7.1 & $\cdots$ & $\cdots$ & $\cdots$ & C \\
\hline Nov. 6, 1958 & 2258:06.0 & 44.45 & 148.62 & 42.5 & $8.3^{*}$ & 225 & 20 & 90 & $\mathbf{A}$ \\
\hline Nov. 12,1958 & $2023: 29.0$ & 44.32 & 148.78 & 17.1 & 7.2 & $\cdots$ & $\cdots$ & $\cdots$ & $\mathrm{C}$ \\
\hline Feb. 12, 1961 & $2153: 43.0$ & 43.84 & 147.65 & 36.6 & 7.2 & $\cdots$ & $\cdots$ & $\cdots$ & $\mathbf{B}$ \\
\hline Aug. 11, 1961 & $1551: 34.0$ & 43.04 & 145.31 & 37.7 & 7.0 & $\cdots$ & $\cdots$ & $\cdots$ & B \\
\hline Nov. 15,1961 & 0717:06.0 & 42.94 & 145.24 & 42.8 & 7.1 & $\cdots$ & $\cdots$ & $\cdots$ & $\mathbf{A}$ \\
\hline March 30, 1963 & $1652: 01.4$ & 44.16 & 148.22 & 41.0 & 6.3 & 193 & 32 & 65 & A \\
\hline Oct. 12,1963 & $1125: 55.0$ & 44.70 & 149.17 & 31.5 & 7.0 & 225 & 30 & 90 & C \\
\hline Oct. 13,1963 & $0517: 51.0$ & 44.69 & 149.61 & 28.3 & $8.5^{*}$ & 223 & 22 & 90 & $\mathrm{C}$ \\
\hline Oct. 13,1963 & 1600:01.8 & 45.56 & 150.57 & 51.7 & 6.3 & 237 & 28 & 114 & A \\
\hline Oct. 20,1963 & 0053:11.0 & 44.73 & 150.51 & 11.9 & 7.0 & 225 & 15 & 90 & C \\
\hline April 8, 1964 & $1058: 12.5$ & 45.75 & 150.96 & 44.0 & 5.5 & 240 & 34 & 121 & A \\
\hline May 31, 1964 & 0040:39.4 & 43.51 & 147.04 & 50.7 & 7.0 & 206 & 26 & 69 & A \\
\hline July 5, 1964 & 2336:00.0 & 44.69 & 149.51 & 21.5 & 5.6 & 225 & 17 & 104 & $\mathrm{C}$ \\
\hline Oct. 16,1964 & 0659:37.6 & 44.48 & 149.72 & 04.2 & 5.6 & 250 & 20 & 128 & $\mathrm{C}$ \\
\hline Oct. 23,1964 & 2106:27.2 & 44.10 & 147.77 & 43.0 & 5.6 & 234 & 29 & 112 & A \\
\hline June 11,1965 & 0333:44.4 & 44.63 & 149.04 & 24.0 & 6.8 & 245 & 21 & 119 & B \\
\hline March 20, 1967 & $1331: 32.3$ & 45.52 & 151.55 & 15.5 & 6.4 & 171 & 17 & 53 & C \\
\hline March 25, 1967 & $2247: 56.7$ & 45.29 & 151.59 & 11.1 & 6.2 & 254 & 18 & 123 & $\mathrm{C}$ \\
\hline April 1, 1967 & $0554: 18.1$ & 45.73 & 151.80 & 14.3 & 6.3 & 229 & 10 & 107 & $\mathrm{C}$ \\
\hline April 1, 1967 & 0557:07.0 & 45.82 & 151.74 & 18.1 & 5.6 & 230 & 11 & 111 & D \\
\hline April 1, 1967 & $1223: 34.8$ & 45.67 & 151.71 & 17.8 & 5.8 & 237 & 13 & 120 & $\mathrm{C}$ \\
\hline Aug. 10, 1967 & $1121: 25.8$ & 45.37 & 150.31 & 41.6 & 5.6 & 238 & 23 & 116 & A \\
\hline Aug. 30, 1967 & $1333: 27.8$ & 45.51 & 151.41 & 20.9 & 5.5 & 232 & 26 & 110 & $\mathrm{C}$ \\
\hline Jan. 29, 1968 & 1019:06.6 & 43.58 & 146.78 & 32.7 & 7.0 & 250 & 29 & 124 & B \\
\hline Jan. 29, 1968 & $1642: 50.6$ & 43.51 & 147.23 & 22.2 & 5.7 & 243 & 18 & 122 & B \\
\hline May 21, 1968 & 0820:01.4 & 44.92 & 150.19 & 17.4 & 6.2 & 185 & 10 & 66 & B \\
\hline May $30,1968 \dagger$ & 0523:47.4 & 44.67 & 150.30 & 21.0 & 5.8 & 240 & 12 & 122 & $\cdots$ \\
\hline Aug. 1, 1969 & $2343: 46.5$ & 45.51 & 150.85 & 31.3 & 5.9 & 223 & 15 & 103 & $\mathrm{C}$ \\
\hline Aug. 11, 1969 & $2127: 35.5$ & 43.53 & 147.95 & 22.7 & 6.5 & 198 & 23 & 106 & $\mathrm{C}$ \\
\hline Aug. 11, 1969 & $2127: 43.6$ & 43.55 & 147.29 & 42.5 & $8.2^{*}$ & 220 & 16 & 90 & D \\
\hline Aug. 11, 1969 & $2127: 41.0$ & 43.80 & 147.70 & $\cdots$ & $8.2^{*}$ & 220 & 16 & 90 & $\cdots$ \\
\hline Aug. 12, 1969 & 0503:25.6 & 43.65 & 148.26 & 08.6 & 6.0 & 256 & 14 & 137 & B \\
\hline Aug. 12, 1969 & $1121: 25.6$ & 44.08 & 148.61 & 32.3 & 6.3 & 250 & 17 & 128 & B \\
\hline Aug. 13, 1969 & 0831:35.9 & 44.10 & 147.81 & 41.0 & 5.6 & 222 & 17 & 106 & A \\
\hline Aug. 13, 1969 & $2257: 09.6$ & 44.24 & 148.35 & 24.9 & 6.1 & 248 & 18 & 127 & B \\
\hline March 10, 1970 & 0458:29.8 & 44.72 & 149.03 & 51.6 & 5.4 & 187 & 33 & 70 & A \\
\hline June 10,1970 & $1617: 47.2$ & 44.84 & 149.67 & 26.0 & 5.5 & 259 & 21 & 141 & C \\
\hline Oct. 8, 1970 & $2336: 15.4$ & 43.87 & 147.44 & 36.6 & 5.6 & 222 & 18 & 106 & B \\
\hline Nov. 20, 1970 & 1348:25.2 & 43.62 & 146.92 & 31.0 & 5.4 & 234 & 22 & 117 & $\mathrm{C}$ \\
\hline Aug. 23, 1971 & $2155: 21.5$ & 45.61 & 150.94 & 44.0 & 5.6 & 255 & 26 & 114 & $\mathbf{A}$ \\
\hline March 25, 1972 & $2259: 42.8$ & 43.39 & 146.07 & 45.6 & 6.0 & 234 & 40 & 122 & A \\
\hline Dec. 10,1972 & $1826: 10.8$ & 44.78 & 149.43 & 22.3 & 5.8 & 245 & 23 & 114 & B \\
\hline Dec. 17,1972 & 0018:33.2 & 44.71 & 149.37 & 19.7 & 5.8 & 241 & 07 & 114 & C \\
\hline June 17,1973 & 0355:04.7 & 43.22 & 145.78 & 44.5 & $7.8^{*}$ & 230 & 17 & 109 & A \\
\hline June 18,1973 & $1745: 44.7$ & 42.51 & 145.94 & 20.1 & 5.5 & 226 & 20 & 86 & A \\
\hline June 24, 1973 & 0243:26.3 & 43.32 & 146.48 & 38.4 & 7.1 & 241 & 26 & 114 & A \\
\hline June 26,1973 & $1802: 23.9$ & 43.00 & 147.08 & 19.5 & 5.8 & 253 & 11 & 128 & B \\
\hline June 26, 1973 & 2232:00.1 & 43.09 & 146.61 & 31.0 & 6.6 & 240 & 16 & 115 & B \\
\hline June 10,1975 & $1347: 17.7$ & 43.13 & 147.54 & 14.0 & 7.0 & 227 & 09 & 87 & C \\
\hline Jan. 21, 1976 & $1005: 22.9$ & 44.79 & 149.27 & 17.5 & 7.0 & 225 & 30 & 90 & B \\
\hline March 19, 1977 & $1056: 24.5$ & 44.25 & 148.28 & 45.5 & 6.0 & 185 & 41 & 80 & A \\
\hline Jan. 13, 1978 & 2003:02.4 & 44.68 & 149.79 & 22.6 & 6.0 & 215 & 26 & 82 & C \\
\hline Jan. 14, 1978 & 0903:16.5 & 44.62 & 149.70 & 27.0 & 5.4 & 223 & 26 & 90 & $\mathrm{C}$ \\
\hline Jan. 24,1978 & $0554: 21.3$ & 44.70 & 149.80 & 19.5 & 5.7 & 214 & 25 & 83 & $\mathrm{C}$ \\
\hline Feb. 9, 1978 & 0802:01.0 & 44.53 & 149.94 & 15.8 & 5.7 & 228 & 30 & 106 & C \\
\hline March 22, 1978 & $0050: 30.0$ & 44.07 & 149.11 & 01.9 & 6.3 & 205 & 07 & 76 & C \\
\hline March 23, 1978 & 0031:00.5 & 44.29 & 149.03 & 15.1 & 7.0 & 225 & 20 & 97 & B \\
\hline March 23, 1978 & 0315:29.1 & 44.80 & 148.23 & 98.2 & 6.1 & 224 & 11 & 91 & D \\
\hline March 23, 1978 & 0350:50.2 & 44.42 & 149.59 & 12.9 & 6.0 & 232 & 40 & 100 & $\mathrm{C}$ \\
\hline March 23, 1978 & $1912: 22.5$ & 44.44 & 149.77 & 06.9 & 6.0 & 209 & 18 & 75 & $\mathrm{C}$ \\
\hline March 24, 1978 & $1947: 49.2$ & 44.24 & 149.02 & 08.0 & 7.6 & 223 & 18 & 93 & C \\
\hline March 25, 1978 & $1140: 29.0$ & 44.12 & 148.75 & 21.3 & 5.3 & 215 & 39 & 90 & C \\
\hline March 25, 1978 & 2352:13.5 & 43.91 & 148.48 & 16.6 & 5.6 & 215 & 25 & 87 & $\mathrm{C}$ \\
\hline Dec. 9,1978 & 0417:07.7 & 45.36 & 150.14 & 47.9 & 5.6 & 239 & 31 & 117 & A \\
\hline Feb. 23, 1980 & 0551:05.4 & 43.60 & 146.70 & 45.1 & 7.0 & 213 & 15 & 89 & A \\
\hline Feb. 19, 1981 & $1936: 13.8$ & 44.74 & 149.40 & 31.2 & 5.9 & 223 & 28 & 91 & B \\
\hline June 5, 1981 & $1941: 55.5$ & 44.77 & 148.92 & 58.6 & 5.9 & 187 & 30 & 61 & A \\
\hline Sept. 3, 1982 $\ddagger$ & 0132:00.7 & 44.01 & 148.39 & 35.0 & 5.9 & 214 & 19 & 81 & $\cdots$ \\
\hline Sept. 3, 1982 & $0340: 11.6$ & 43.95 & 148.42 & 13.2 & 5.7 & 202 & 19 & 61 & C \\
\hline Sept. 3, 1982 & $0828: 33.9$ & 43.85 & 148.48 & 03.9 & 5.6 & 201 & 23 & 61 & $\mathrm{C}$ \\
\hline
\end{tabular}


TABLE 1. (continued)

\begin{tabular}{|c|c|c|c|c|c|c|c|c|c|}
\hline Date & $\begin{array}{c}\text { Time, } \\
\text { UT }\end{array}$ & $\begin{array}{l}\text { Latitude, } \\
{ }^{\circ} \mathrm{N}\end{array}$ & $\begin{array}{c}\text { Longitude, } \\
{ }^{\circ} \mathbf{E}\end{array}$ & $\begin{array}{l}\text { Depth, } \\
\text { km }\end{array}$ & $M_{s}$ & $\begin{array}{l}\text { Strike, } \\
\text { deg }\end{array}$ & $\begin{array}{l}\text { Dip, } \\
\text { deg }\end{array}$ & $\begin{array}{c}\text { Rake, } \\
\text { deg }\end{array}$ & QU† \\
\hline Nov. 4, 1982 & 0929:54.4 & 44.09 & 148.06 & 30.4 & 5.6 & 204 & 19 & 50 & B \\
\hline March $10,1983 \ddagger$ & $0027: 49.9$ & 43.88 & 147.42 & 31.0 & 6.1 & 218 & 26 & 88 & $\cdots$ \\
\hline June 6,1983 & $2140: 21.2$ & 45.38 & 150.32 & 42.0 & 5.6 & 239 & 26 & 114 & A \\
\hline June $30,1983 \ddagger$ & 1339:05.1 & 44.09 & 147.86 & 27.0 & 5.6 & 251 & 25 & 123 & $\cdots$ \\
\hline Nov. 20,1983 & $0044: 44.3$ & 43.88 & 148.39 & 16.1 & 5.9 & 223 & 17 & 90 & B \\
\hline Dec. $24,1983 \ddagger$ & $0410: 45.2$ & 45.50 & 151.36 & 26.0 & 5.7 & 198 & 27 & 56 & $\cdots$ \\
\hline Jan. 4,1984 & $2240: 43.1$ & 45.59 & 151.34 & 26.0 & 6.0 & 240 & 18 & 102 & $\mathrm{C}$ \\
\hline March 16, 1984 & $1710: 48.8$ & 43.05 & 145.36 & 45.4 & 5.6 & 234 & 41 & 97 & $\mathbf{A}$ \\
\hline March 24, 1984 & 0944:01.4 & 44.20 & 148.33 & 18.6 & 7.0 & 229 & 17 & 109 & $\mathbf{B}$ \\
\hline Sept. 1,1984 & $1705: 53.7$ & 44.45 & 149.63 & 07.2 & 5.8 & 230 & 30 & 113 & $\mathrm{C}$ \\
\hline Dec. 3,1984 & $0408: 35.0$ & 44.28 & 148.22 & 44.3 & 6.3 & 181 & 40 & 61 & A \\
\hline Dec. 17,1984 & $2330: 23.6$ & 44.52 & 149.13 & 28.1 & 6.0 & 226 & 21 & 98 & B \\
\hline Dec. 17,1984 & $2356: 58.4$ & 44.43 & 149.13 & 16.4 & 6.0 & 226 & 30 & 100 & $\mathrm{C}$ \\
\hline Dec. 18,1984 & $1732: 43.3$ & 44.30 & 149.15 & 09.4 & 5.7 & 217 & 20 & 87 & D \\
\hline Feb. 2, 1985 & $1106: 48.7$ & 43.93 & 147.60 & 44.0 & 5.5 & 218 & 32 & 79 & $\cdots$ \\
\hline April 16, 1986 & $1252: 20.9$ & 43.96 & 147.50 & 35.0 & 6.3 & 230 & 26 & 108 & $\cdots$ \\
\hline May 21,1986 & 0547:09.4 & 43.92 & 148.41 & 06.8 & 6.1 & 231 & 19 & 108 & $\mathrm{C}$ \\
\hline
\end{tabular}

${ }^{*} M_{w}$.

†QU is hypocentral quality factor where quality $\mathrm{A}, \mathrm{B}$, and $\mathrm{C}$ hypocenters all have epicenter confidence ellipses that are less than $15 \mathrm{~km}$ but have hypocenter confidence ellipsoids that are less than $15 \mathrm{~km}$, between 15 and $20 \mathrm{~km}$, and greater than $20 \mathrm{~km}$, respectively. Quality D hypocenters have epicentral uncertainties that exceed $15 \mathrm{~km}$; these hypocenters are not shown on the figures. Two hypocenters are listed for the great 1969 earthquake; the first was determined by JHD and the second by a non-JHD method (see text for discussion).

$\ddagger$ Earthquake depths determined from waveform modeling.

along the entire arc, the first step of our procedure uses only data from distances greater than $27^{\circ}$. However, nearby stations are necessary to estimate focal depths if only $P$ wave and $S$ wave first arrival times are being used to calculate depths. Moreover, for stations at any distance one would generally expect that the smaller the source region from which earthquakes were being located, the more likely that the source-receiver anomaly is the same for all sources. Hence the second step, which produces the final station corrections, uses nearby stations and groups events into quadrangles that are about one-third the length of the entire arc segment.

The third step of the JHD-based location process formally abandons the JHD equations of condition in favor of single event equations of condition, but, for events located by JHD in step 2, the hypocenters produced in step 3 are identical. The hypocenters are identical because the station corrections and weighting functions used in the single event equations of condition are those that were computed by JHD in step 2. Our separation of steps 2 and 3 in the location procedure enables us to treat problem events (such as those for which the inversion of arrival time data would literally imply a focus above the Earth's surface) singly, so that these events do not introduce instability into the entire JHD computation. The confidence ellipsoids produced in the third stage are computed from the single event equations of condition, using the method of Evernden [1969] with variances set equal to those computed in the JHD computation.

The earthquakes of March 10, 1983, and December 24, 1983, were selected as calibration events to be used in the second step for the two westernmost and two easternmost overlapping quadrangles, respectively. Epicenters for the calibration events were determined in a JHD run, in which the mathematical conditions necessary to make the JHD computation stable were provided by calibration station corrections rather than by a calibration event [Dewey, 1983]. The particular calibration station corrections chosen, the azimuthally dependent station corrections of Dziewonski and Anderson [1983] for 30 well-distributed stations, were selected to minimize location bias arising from travel time anomalies beneath the stations. These calibration station corrections do not account for velocity anomalies associated with the subducted Kurile Islands slab.

The epicenter confidence ellipses and hypocenter confidence ellipsoids, upon which our quality factors are based (Table 1), themselves depend on a number of assumptions and approximations. The JHD-computed variances are assumed to be appropriate for all events, including those occurring in the coda of previous earthquakes: if arrival times for a particular event are contaminated by noise with higher variances than the JHD-computed variances, the confidence regions computed for that event would be unrealistically small. The ellipses and ellipsoids incorporate the JHD assumption that travel time anomalies can be represented as station terms, and they are constructed from linearized equations of condition [Flinn, 1965]. On the basis of previous studies in which we could compare JHD epicenters with independently known epicenters [Dewey, 1972; Dewey and Gordon, 1984], we view the epicenter ellipses as providing reasonable estimates of precision within a small area of the plate interface but as more likely corresponding to a 70 or $80 \%$ level of confidence rather than the " $90 \%$ level of confidence" formally attached to them. Our experience suggests that the hypocenter ellipsoids might likewise correspond to a 70 or $80 \%$ level of confidence. However, nonlinear effects, which could make the ellipsoids either more or less conservative, appear to be more troublesome when estimating confidence intervals involving focal depth than when estimating confidence regions on epicentral coordinates alone.

\section{Depth Determinations}

The most accurate earthquake depths are usually those obtained through direct observation of the surface reflected phases $p P$ and $s P$. In subduction zones the sea surface reflection $p w P$ is also observed and can be used for accurate 
TABLE 2. Velocity Models

\begin{tabular}{ccccc}
\hline $\begin{array}{c}\text { Depth, } \\
\mathrm{km}\end{array}$ & $\begin{array}{c}v_{p}, \\
\mathrm{~km} / \mathrm{s}\end{array}$ & $\begin{array}{c}v_{s}, \\
\mathrm{~km} / \mathrm{s}\end{array}$ & $\begin{array}{c}\text { Density, } \\
\mathbf{g} / \mathrm{cm}^{3}\end{array}$ \\
\hline & & Model 1 & & \\
$X$ & 1.5 & & 0.0 & 1.0 \\
20. & 6.4 & & 3.7 & 2.7 \\
& 7.75 & & 4.4 & 3.3 \\
$X$ & & Model 2 & & \\
20. & 1.5 & & 0.0 & 1.0 \\
& 6.7 & & 3.9 & 2.7 \\
& 8.1 & & 4.7 & 3.3 \\
$X$ & & Model 3 & & \\
2.0 & 1.5 & & 0.0 & 1.0 \\
4.0 & 2.5 & & 1.4 & 1.7 \\
14. & 5.0 & & 2.8 & 2.2 \\
& 6.4 & & 3.7 & 2.7 \\
\hline
\end{tabular}

$X$ is dependent on local bathymetry.

focal depth determination [Engdahl and Billington, 1986]. The increased bandwidth of broadband data can vastly improve the quality of observed depth phases, often allowing their unequivocal identification in the case of simple events [Choy and Engdahl, 1987]. However, to ensure proper identification of the depth phases for complicated source regions, waveform modeling may be needed in depth analysis. Focal depths computed in this study are tied to focal depths determined by means of waveform modeling for the two calibration events and five additional earthquakes. All modeled events have $M_{s} \leq 6.3$. The focal depths of the modeled earthquakes are restrained in the JHD computation. Focal depths of nonmodeled earthquakes are calculated from the first arrivals of $P$ and $S$ waves and are related to the depths of the modeled events by means of the JHDcomputed station corrections.

For the waveform modeling, we used the approach of Langston and Helmberger [1975] to compute synthetic seismograms for shallow sources embedded in a layered medium. The seismogram is treated as a sum of rays for which amplitudes and delay times are determined by the geometry of the source and the thicknesses and velocities of the layers traversed. This ray sum is then convolved with a propagation term consisting of the geometric spreading factor and attenuation operator, a near-receiver term consisting of the effect of the free surface interaction, the instrument response, and the source time function of the earthquake. For larger earthquakes the trade-off between focal depth and source complexity can be quite severe; however, Stein and Wiens [1986] found that this trade-off is usually small and does not cause difficulties in depth determinations for earthquakes with $M_{s} \leq 6.5$.

We modeled selected broadband vertical seismograms recorded by stations of the Regional Seismic Test Network (RSTN) and the Digital Worldwide Standardized Seismograph Network and long-period seismograms recorded by stations of the Worldwide Standardized Seismograph Network (WWSSN). One of the three near-source layered velocity structures listed in Table 2 was used in construction of the synthetic seismograms depending on which provided a better fit to the observed data. Synthetic seismograms were matched to the observed data by varying the depth and source time function; absolute amplitudes were not pre- served, preventing the determination of seismic moments for each event. The focal mechanisms were assumed to be those listed in Table 1; a representative focal mechanism is shown in Figure 1.

Observed and synthetic seismograms and arrival spike trains for the seven events modeled are shown in Figure 2. Azimuthal changes in the observed waveforms, caused by variations in the relative amplitudes of the depth phases, are well modeled for the four events in the top row of Figure 2. For the remaining three events (bottom row of Figure 2), seismograms from only one station or several stations at similar azimuths from the source were modeled.

Assuming that focal depths of the earthquakes with modeled $P$ waveforms are reliable, there remain sources of uncertainty in the depths calculated with the JHD method. These depth determinations are sensitive to the arrival times at regional Japanese and Soviet stations and are therefore sensitive to violations of the JHD assumption that sourcereceiver travel times are constant to a given regional station from all earthquakes in a several hundred kilometer long, 100-km-wide, section of the Kurile Islands Arc. In addition, the JHD method cannot avoid the uncertainty that arises from the fact that the range in source-receiver takeoff angles is small for the shallower of the earthquakes being located.

\section{RESULTS}

Our relocated hypocenters are listed in Table 1, and all but those of the lowest quality rating are plotted together with their International Seismological Center (ISC) locations in map and cross-sectional view in Figures 1 and 3 . The great earthquake asperities shown in Figure 1 are those of Schwartz and Ruff [1987], repositioned with respect to the great earthquake epicenters. Two epicenters are given in Table 1 for the great earthquake of 1969. The first is that determined by the method of this study; this location is relatively poor due to the occurrence of a small foreshock just seconds earlier, which obscurred the main shock's arrival at many stations. The second epicenter of the 1969 main shock was computed relative to the JHD location of the foreshock from arrival time differences (main shock minus foreshock) observed on 17 WWSSN long-period records. It is this second location that is plotted in subsequent figures.

The most dramatic effect of the earthquake relocations is due to changes in focal depth; the revised hypocenters are much more suggestive than the routinely determined hypocenters of an inclined seismic zone extending inland from the trench (Figure 3). Changes in epicenters that are most significant for the purposes of this study are changes in the positions of the epicenters of the great earthquakes of 1963 and 1969 with respect to the epicenters of smaller earthquakes in their aftershock zones (Figure 1). This is important because the locations of the asperities are determined by the great earthquake epicenters. There is also a tendency for relocated epicenters in some regions (e.g., near $44.4^{\circ} \mathrm{N}$, $149.7^{\circ} \mathrm{E}$, near $43.9^{\circ} \mathrm{N}, 148.4^{\circ} \mathrm{E}$, and near $43.0^{\circ} \mathrm{N}, 145.3^{\circ} \mathrm{E}$ ) to cluster in smaller areas of the interface than the previous epicenters. The width and absolute position of the seismogenic interface in map view are not significantly changed by the recalculation of hypocenters (Figure 1).

\section{Absolute Accuracy of Epicenters}

Our epicenters probably contain some bias that is not accounted for in the confidence ellipses or confidence ellip- 

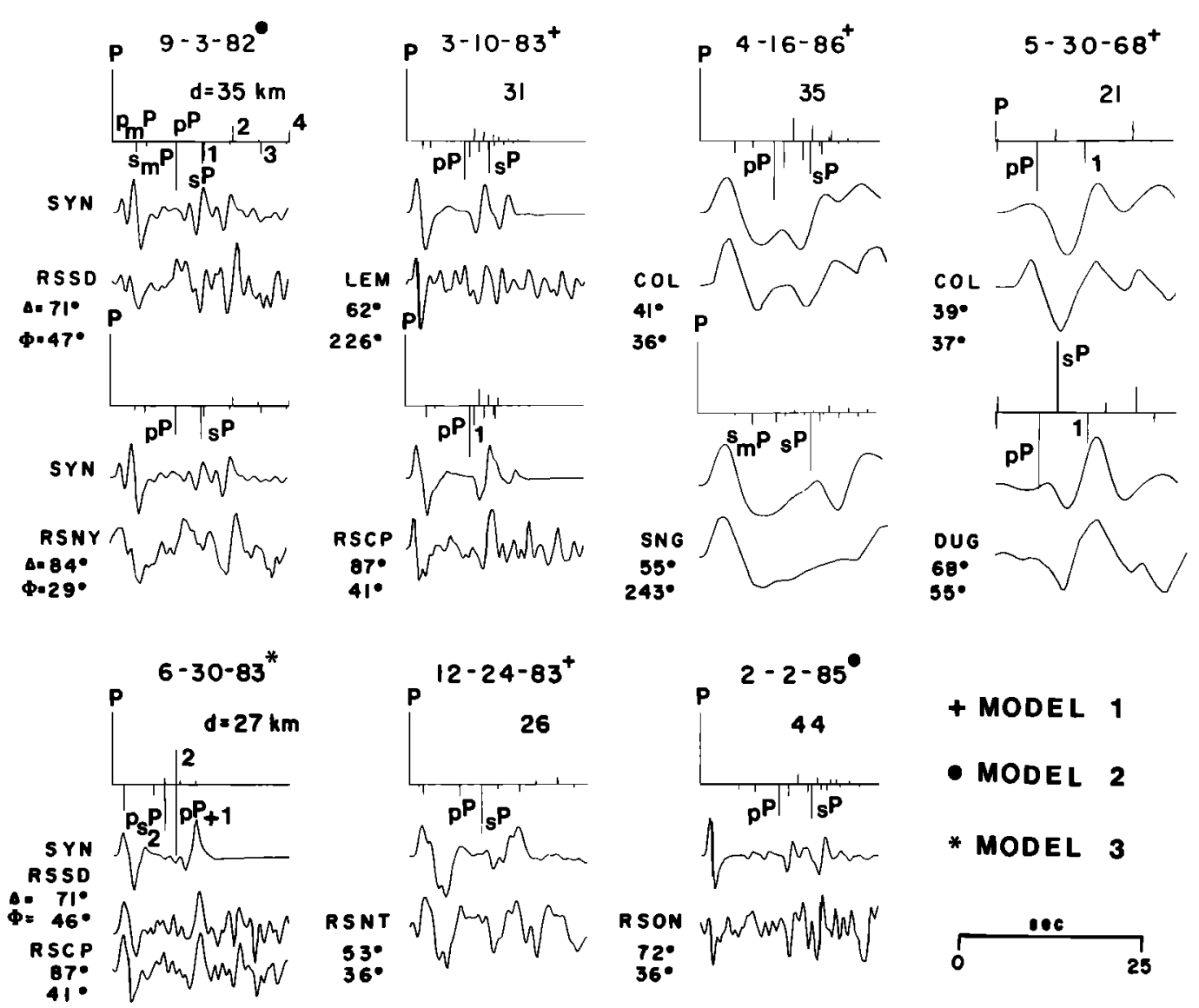

Fig. 2. Comparison of observed and synthetic $P$ waveforms for seven southern Kurile Islands events. The relative amplitudes and arrival times of the direct and reflected phases, including the effects of source geometry, are shown as the top trace for each event. Most phases are labeled for the recording of September 3, 1982; in all other cases only the most significant phases are labeled; $p_{m} P, p_{s} P, p P, s_{m} P$, and $s P$ represent $P$ and $S$ waves reflected from the Moho (m), a low-velocity sedimentary layer(s), and the seafloor, respectively. The numbers on the spike trains correspond to consecutive water bounces $p_{w} P, p_{w 2} P$, etc. The model number refers to velocity models listed in Table 2 .

soids. One might expect a priori that the bias would be toward the northwest, because of high mantle velocities to the northwest of the trench that are associated with the subducted Pacific plate. The presence of bias in our entire group of epicenters would not effect the conclusions of this paper, but it would be important if our epicenters were to be used to test hypotheses on the position of the seismogenic thrust interface with respect to topographic features of the accretionary wedge [e.g., Byrne et al., 1988].

Comparison of our epicenters with those of Fedotov et al. [1969] suggest that bias of $10-20 \mathrm{~km}$ could be present in our data, but we do not see evidence for biases approaching the $40-50 \mathrm{~km}$ observed in underthrusting events in the Aleutian Islands [Engdahl et al., 1982]. The locally recorded epicenters of Fedotov et al. [1969] should, in general, be less susceptible to bias than teleseismically determined epicenters, and they should not be affected by the same velocity anomalies as those biasing teleseismic epicenters. For the 15 earthquakes that we located in 1958-1964, our epicenters are displaced systematically to the north with respect to epicenters reported by Fedotov et al. [1969], but there is no systematic shift in longitude. The median northward shift is $15 \mathrm{~km}$. The downdip edges of locally recorded clusters of activity associated with known underthrusting earthquakes [Fedotov et al., 1969] are within $10 \mathrm{~km}$ of the downdip edge of our teleseismically determined seismogenic interface.

\section{Along-Dip Properties of the Plate Interface}

The seismogenic thrust interface in the southern Kurile Islands Arc, from the trenchward "tsunamigenic" earthquakes to the deepest underthrusting events, has a width of approximately $80 \mathrm{~km}$ in map view (Figure 1) and extends in depth from 5 to $10 \mathrm{~km}$ beneath the ocean floor at the updip edge to about 50 or $60 \mathrm{~km}$ at the downdip edge. The width of the seismogenic interface measured along dip is about 100 $\mathrm{km}$. The strongest contraints on the depths of the trenchward earthquakes are the focal mechanisms and tsunamigenic characteristics of some of the events, which suggest that the earthquakes occur on and above the 5- to 10$\mathrm{km}$-deep boundary separating the accretionary wedge from the underlying Pacific lithosphere [Fukao, 1979]. Our estimate of 50 or $60 \mathrm{~km}$ for the base of the seismogenic zone takes into account the uncertainty implied by the confidence ellipsoids associated with our deep hypocenters. Our findings on the maximum depth of plate boundary earthquakes is consistent with results of Veith [1974], who relocated a large number of earthquakes that occurred in the southern Kurile Islands Arc between 1964 and 1971 using station and source region corrections that were calibrated by bulletin reported depth phases.

Allowing for uncertainty in both focal mechanisms and hypocenters, the data are consistent with events occurring 

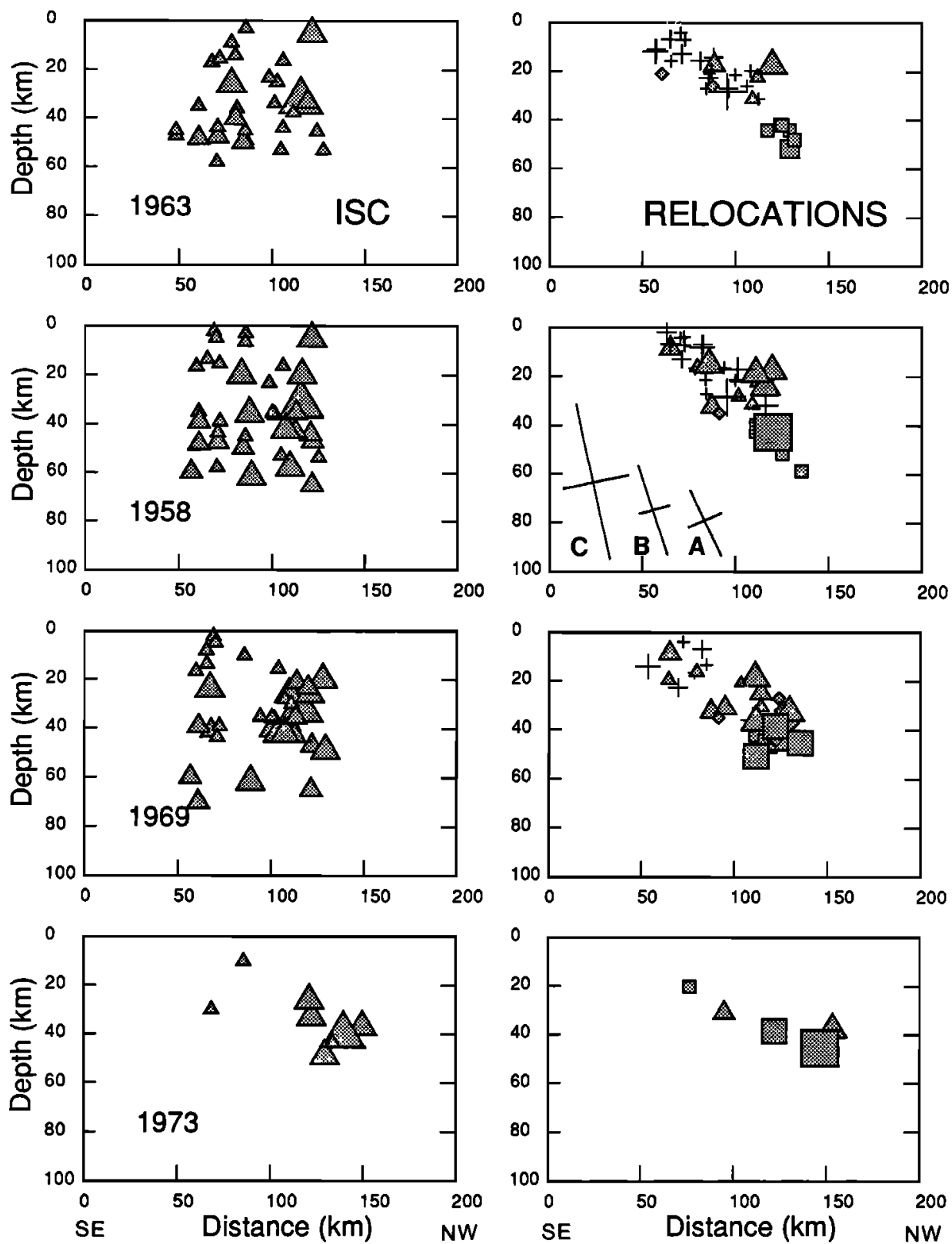

Fig. 3. Depth profiles of the ISC (left) and relocated (right) interplate seismicity occurring in the aftershock zones of the four largest southern Kurile Islands events. The distances are measured from the trench axis $(0 \mathrm{~km})$. Symbol size is scaled according to four earthquake magnitude ranges $\left(5.0 \leq M_{s}<6.0,6.0 \leq M_{s}<7.0,7.0 \leq M_{s}<8.0\right.$, and $M_{s} \geq$ 8.0). Quality A, B, and C relocated hypocenters are indicated by the squares, triangles, and pluses, respectively. The diamonds identify events for which depths were determined by waveform modeling. Projections of the largest hypocenter ellipsoids for events of A, B, and C quality are shown in the panel of relocated earthquakes from the 1958 zone.

as slip on a single interface between the subducting Pacific plate and the overriding Eurasian plate. Following the common plate tectonic model in which subduction is predominately accommodated on a single megathrust, we will refer to the plate boundary as an interface. In a broad sense, the distribution of our epicenters shows a tendency for large earthquakes to occur in the deep parts of the seismogenic plate interface. Thus most of the identified underthrusting events of magnitude $\geq 7$ and the great earthquakes of 1958 and 1973 nucleated near the downdip edge of the plate interface (Figure 1).

The concentration of moment release at the downdip half of the seismically active plate interface is similar to the behavior observed in continental fault zones. Many continental fault zones exhibit a sharp decline in the number of earthquakes below about $15 \mathrm{~km}$ with the largest events nucleating near this cutoff depth [Sibson, 1984]. These observations have been interpreted in terms of a transition in the rheology of the fault zone from a frictional regime above the cutoff depth of seismic activity to a plastic regime below it [Sibson, 1984] or in terms of unstable slip above and stable slip below [Tse and Rice, 1986]. Within a petrologically uniform frictional or unstable slip regime, shear resistance should generally increase with depth, provided that pore fluid pressures increases less rapidly with depth than lithostatic pressure normal to the fault. This would account for 


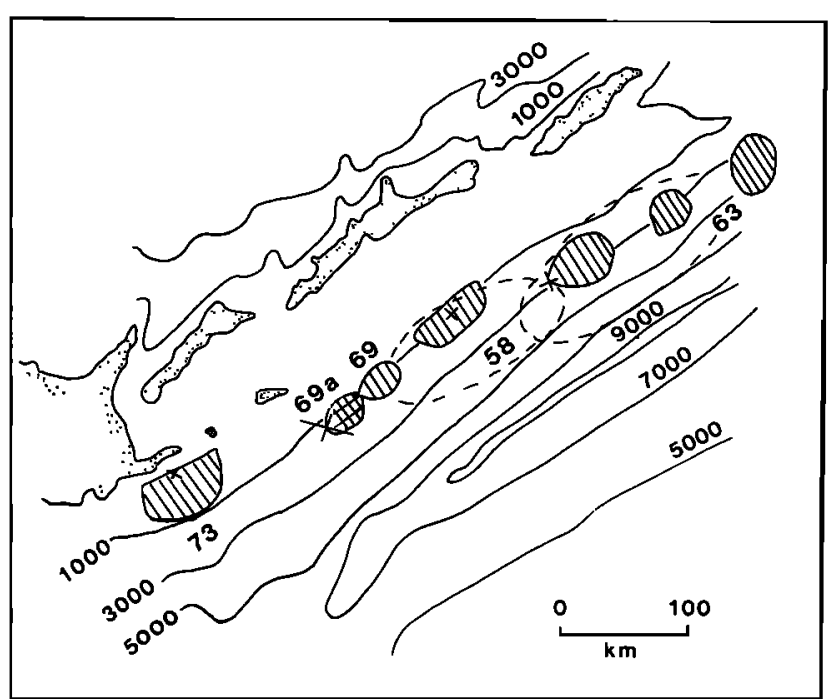

Fig. 4. Principal axes of confidence ellipses are plotted at each of the JHD great earthquake epicenters. Uncertainties in asperity locations (hatchured areas) are subject to the uncertainties implied by the confidence ellipses, in addition to uncertainties associated with the definition of the asperities. Two alternative asperities are plotted here for the great 1969 earthquake: " 69 " is centered on the epicenter determined with the non-JHD method, and "69a" is centered on the quality D epicenter determined by JHD. Dashed lines enclose source regions of the 1958 and 1963 great earthquakes, as inferred by Fedotov et al. [1969] from the distribution of early, locally recorded aftershocks. Bathymetric contours are also labeled.

localization of large earthquakes near the base of the frictional or unstable regime [Sibson, 1984; Das and Scholz, 1983]. Similar reasoning would seem also to apply to subduction zone environments, although the transition in subduction zones would be deeper than in intracontinental regions due to the depression of isotherms and to high pore fluid pressures in subducted sediments [e.g., van den Beukel and Wortel, 1987].

The tendency for large earthquakes to nucleate near the downdip edge of the Kuriles Islands thrust interface is not, however, absolute. The great earthquake of 1963 and possibly that of 1969 nucleated tens of kilometers from the downdip edge of the seismogenic interface. Their dominant asperities, which are positioned with respect to their epicenters, therefore plot noticeable updip from the base of the seismogenic interface (Figure 1). The magnitude 7.6 earthquake of March 24, 1978, was also centered in the middle of the seismogenic zone. These are in addition to the anomalously tsunamigenic earthquakes of October 20, 1963, and June 10, 1975, which occurred at the updip edge of the seismogenic interface. The latter two earthquakes have been postulated to have had much of their moment released within the accretionary wedge above the interface between the Pacific plate and the overlying sediments [Fukao, 1979].

The great 1963 earthquake was well recorded, and its epicenter (though not its focal depth) has a small associated confidence ellipse (Figure 4). The entire confidence ellipse associated with this event is $20 \mathrm{~km}$ or more seaward of the average position of the downdip edge of the seismogenic zone. The positions of the 1963 asperities [Beck and Ruff, 1987] are less precisely determined than the epicenter with respect to which the asperities are located. Nonetheless, the seaward shift of the 1963 asperities compared with the 1958 asperity is quite similar to the shift of the 1963 source region compared with the 1958 source region as reported by $\mathrm{Fe}$ dotov et al. [1969] based on the distribution of early, locally recorded aftershocks (Figure 4).

As noted previously, the epicenter of the 1969 main shock is not well determined, but our two alternative solutions are seaward of the downdip edge of the seismogenic interface. Several underthrusting events occur downdip of the 1969 asperity regardless of which epicentral location is assumed (Figure 1). The occurrence of major asperities at middle depths of the seismogenic interface implies that the general increase in shear resistance with increase in lithostatic pressure is counteracted by compositional changes or tectonic processes that produce at least a local reduction in shear resistance on the plate interface between the asperities and the base of the seismogenic interface. Changes in the petrology of the faulted media or pore fluid pressures substantially above hydrostatic, which have been proposed as modifying the simple depth dependent increase of shear resistance in continental regions [Chen and Molnar, 1983; Sibson, 1984], might also be responsible for local downdip decreases in shear resistance on the plate interface in the Kurile Islands Arc. Possibly, gravitational loading by the overriding plate could also produce high stresses (asperities) at middle depths of the plate interface [Reyners and Coles, 1982].

Currently available evidence suggests that along-dip variations in asperity locations may be different for different subduction zones. Choy and Dewey [1988] found that the portion of the Chilean subduction zone which failed in the great March 3, 1985, underthrusting earthquake consisted of a strongly coupled downdip portion and a more weakly coupled updip section. They made the distinction in the degree of mechanical coupling on the basis of higher stress drops calculated for events occurring along the deeper interface compared with those calculated for events occurring at shallower depths. They also reported a higher proportion of large to small earthquakes occurring on the deeper thrust interface. Choy and Dewey [1988] interpreted their results as being consistent with arguments made in continental environments that maximum friction on a fault zone should occur near the base of the seismogenic zone. On the other hand, from the analysis of local network data recorded in the central New Hebrides Island Arc, Chatelain et al. [1986] found that the updip portion of the subducted plate interface was responsible for generating the larger earthquakes compared with the downdip section. Similarly, Kawakatsu and Seno [1983] found evidence in northern Honshu for downdip variations in the size of major underthrusting earthquakes, with the great events occurring in a shallow thrust zone $(0-40 \mathrm{~km})$ and the smaller, but still large, earthquakes occurring in a deep thrust zone $(40-60 \mathrm{~km})$ that is spatially separated from the shallow zone.

It is apparent that the along-dip variations in the mechanical properties of the plate interface can exert a strong influence on seismic moment release along an entire arc segment. This realization adds a new dimension to the asperity model, which has usually been invoked to explain along-strike variations in observed seismic behavior. In addition to describing the along-strike changes in the material properties of the fault plane, our concept of the asperity model must be expanded to accommodate along-dip variations as well. The along-strike segmentation of the Kurile Islands thrust interface may in fact be determined by along- 


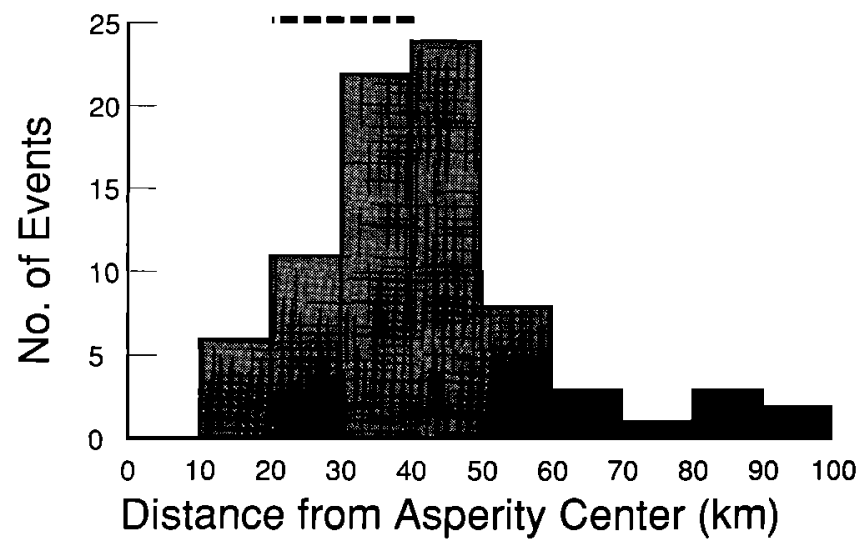

Fig. 5. Histogram of relocated epicentral distance from neares great earthquake asperity center. Few earthquakes occur within 20 $\mathrm{km}$ of an asperity center. The dashed bar indicates the range in great earthquake asperity radii. A peak in this distribution coincides with the range of asperity radii, suggesting a clustering of earthquakes at asperity edges.

strike variations in the processes that control the along-dip changes in shear resistance. It is noteworthy that the source regions of the four great earthquakes studied here appear to be located alternately at middle and deep depths of the interface. Alternation of the largest asperities between the deep interface and the middle interface and the associated time delays necessary for strain to propagate along-dip between asperities may account for the observation $[\mathrm{Fe}$ dotov et al., 1969] that rupture of the great Kurile Islands earthquake of 1958 did not immediately trigger the faulting that was to occur in 1963,1969 , and 1973 , although the entire $700-\mathrm{km}$-long arc segment was in 1958 approaching the end of a seismic cycle.

\section{Influence of Strain Release in Great Earthquake Asperities on Seismicity Patterns}

Few of the relocated hypocenters occur within the great earthquake asperity regions (Figure 1). This relationship is illustrated graphically in Figure 5 which shows a histogram of the distance between each event and the center of the nearest asperity. The approximate range in observed main shock asperity radii for the four great Kurile Islands earthquakes is indicated by the dashed bar in Figure 5 (25-45 km). While few events occur within $20 \mathrm{~km}$ of an asperity center, a peak in earthquake distance from the asperity center coincides with the observed range of asperity radii. This may suggest a tendency for events to occur at asperity edges. However, since the asperities themselves differ in size and their dimensions in the along-dip direction are not well constrained from seismic observations [Schwartz and Ruff, 1987], this suggestion is rather speculative. Figure 6 shows depth and time profiles of relocated hypocenters projected along a southwest-northeast line, parallel to the trend of the southern Kurile Islands Arc. The approximate locations of the asperities associated with each great earthquake are hatchured, and once again we see that few events locate within asperity regions.

Over $85 \%$ of the relocated earthquakes occurred subsequent to failure of their nearest great earthquake asperity (Figure 6). Therefore the lack of earthquakes occurring within asperities suggests that substantial release of accumulated strain energy takes place in asperity regions upon their failure. Too few of the relocated earthquakes occurred prior to asperity failure to ascertain whether or not asperity regions experience slip or remain locked before their rupture in a large underthrusting event.

Several studies of stress regimes in subducted lithosphere have suggested that intraplate seismic behavior in subduction zones is influenced by regional changes in the stress regime at the interplate contact caused by the occurrence of a large underthrusting earthquake [e.g., Christensen and Ruff, 1983, 1988; Astiz and Kanamori, 1986; Dmowska et al., 1988; Lay et al., 1988]. If this is true, one might expect that intraplate activity would be concentrated near asperities on the plate interface, which experience the largest displacements and stress fluctuations during the earthquake cycle. To test this hypothesis, we have constructed depth profiles of intraplate earthquakes with depths less than $100 \mathrm{~km}$ (Figure 7). The events shown in Figure 7 were taken from a comprehensive catalog of intraplate events constructed by Lay et al. [1988]. Although the intraplate hypocenters have not been redetermined and are therefore less reliable than the interplate hypocenters, there does appear to be a weak association between asperity and intraplate earthquake locations. Intraplate events with downdip tensional ( $t$ in Figure 7), downdip compressional (c in Figure 7), or obliquely oriented tension or compression axes ( $\mathrm{x}$ in Figure 7 ) show a tendency to occur updip or downdip of asperity regions or at asperity edges (Figure 7).

Global analyses of the temporal variation of large intraplate earthquakes in seismically coupled subduction zones [Christensen and Ruff, 1988; Lay et al., 1988] have revealed that outer rise compressional events and intermediate depth tensional events tend to occur prior to large thrust events, while outer rise tensional and intermediate depth compressional events generally follow large thrust events. In the southern Kurile Islands Arc, Christensen and Ruff [1988] found five outer rise tensional events following the great 1963 underthrusting earthquake and one tensional outer rise event following the great 1958 event. Five of these events (shallowest tensional events in Figure 7) locate in the outer rise either directly seaward of the great earthquake asperity regions or seaward of an asperity edge. No known compressional outer rise events have occurred in this region. Lay et al. [1988] characterized the intermediate depth intraplate seismicity in the southern Kurile Islands region as complex. Here a mixture of tensional, compressional and oblique faulting occurs; however, its relationship to the great thrust events is inconsistent with the temporal variations of intraplate activity recognized globally [Lay et al., 1988].

\section{CONCLUSIONS}

Relocation of hypocenters of 87 underthrusting earthquakes in the southern Kurile Islands Arc defines the dimensions of the seismogenic interface between the Pacific and Eurasian plates and determines the positions of major asperites within the seismogenic interface.

The seismogenic interface is approximately $100 \mathrm{~km}$ wide, measured from the hypocenters of the deepest earthquakes updip to the hypocenters of shallow anomalously tsunamigenic earthquakes, and extends over depths ranging from about $50 \mathrm{~km}$ to several kilometers beneath the seafloor.

An along-dip or depth dependent component of stress heterogeneity exerts a strong control on the observed seismicity. Most of the $M_{s} \geq 7$ earthquakes and the principal 

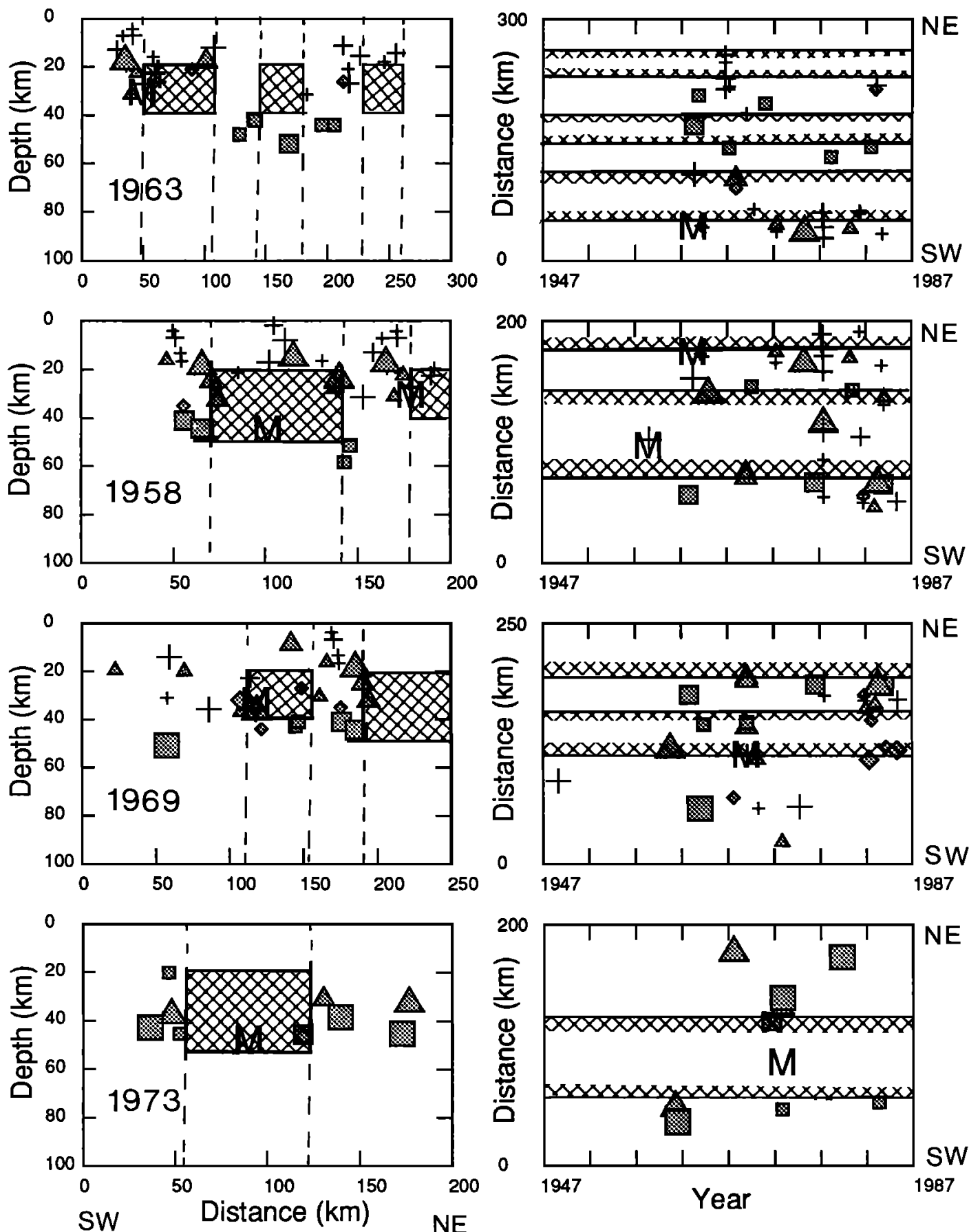

Fig. 6. Depth and time profiles of interplate seismicity occurring in the aftershock zones of the four great southern Kurile Islands earthquakes. Distances are measured along a great circle parallel to the arc. Symbol convention is the same as in Figure 3 with in addition $M$ representing the hypocenter of each great earthquake and hatchured regions delineating the approximate locations of their associated asperities.

asperities of the great earthquakes of 1958 and 1973 are located near the downdip edge of the seismogenic interface. The occurrence of large asperities near the downdip edge of the seismogenic interface would be expected from models, such as those applied to continental fault zones, that predict a monotonic downward increase in friction across faults in the brittle crust and mantle until a maximum is reached just above the brittle-ductile transition. However, the principal asperities of the great 1963 earthquake are located at middle depths within the seismogenic interface, 30 or $40 \mathrm{~km}$ updip from the deepest earthquakes in their section of the arc. The principal asperity of the great 1969 earthquake is also most likely located tens of kilometers updip of the base of the seismogenic zone. In the 1963 and 1969 sections of the arc, some process apparently counteracts the downdip increase in friction predicted to occur if the wall rocks of the interface were petrologically homogeneous along-dip and if pore fluid pressure increased linearly at a rate less than the rate of lithospheric pressure. Along-strike changes in along-dip positions of the major asperities may cause the along-strike seismotectonic segmentation of the southern Kurile Islands Arc. 

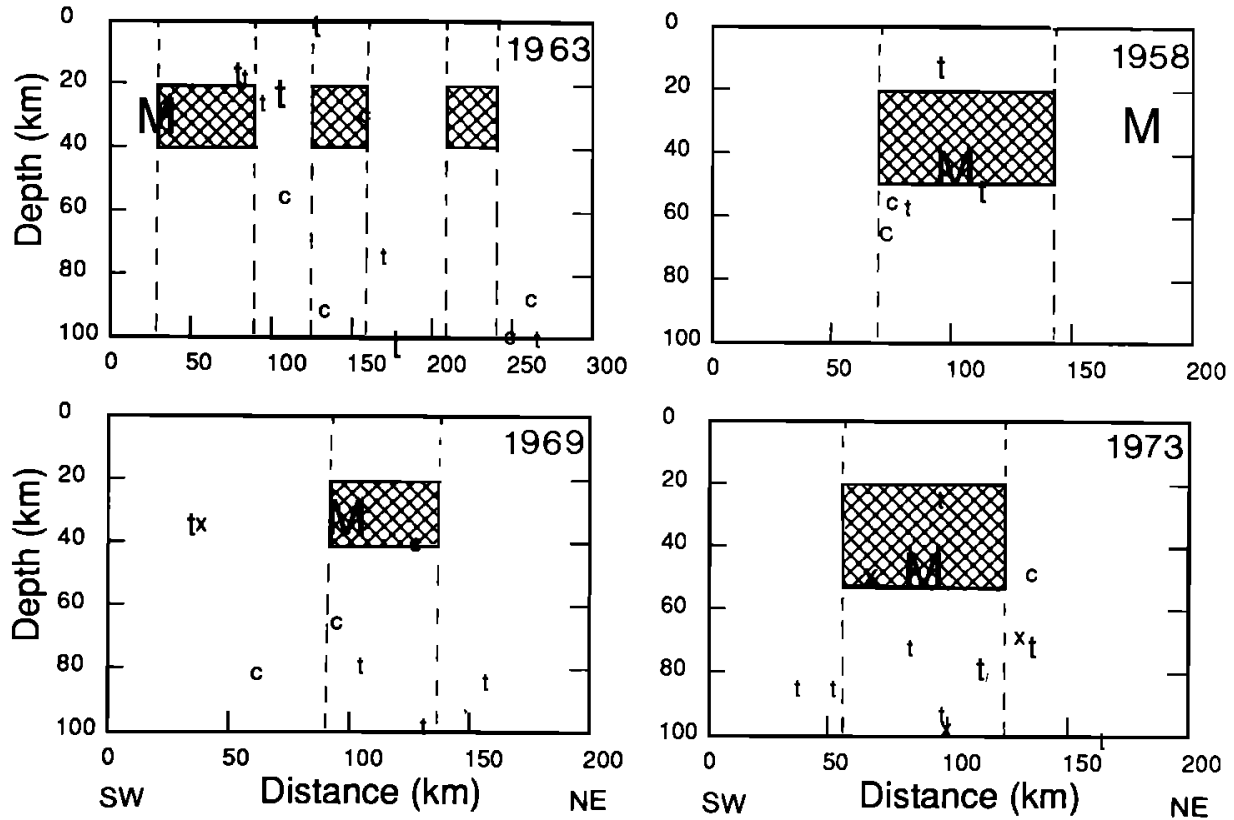

Fig. 7. Depth profiles of intraplate seismicity occurring in the aftershock zones of the four great southern Kurile Islands earthquakes as in Figure 6. Symbol size is proportional to earthquake magnitude. The great earthquake hypocenters, tensional, compressional, and tear/oblique events are indicated by $M, t, c$, and $x$ respectively. The hatchured regions represent the locations of the principal asperities; the dashed lines represent their along-dip extensions.

The distribution of earthquake hypocenters with respect to the asperities of the great earthquakes of $1958,1963,1969$, and 1973, identified by Schwartz and Ruff [1987], reveals that nearly all of the smaller-magnitude earthquakes are located outside of the asperities. A similar result has been obtained in recent studies of other major earthquakes. The observation is, in retrospect, not surprising, because strain energy should be substantially reduced on patches of the fault interface that produce the greatest moment release. But the observation provides additional evidence against the assumption, sometimes made if asperities have not been independently imaged, that clusters of intense aftershock activity correspond to main shock asperities.

Acknowledgments. We wish to thank the USGS and Sandia National Laboratories for providing us with GDSN and RSTN data. We are also grateful to Larry Ruff, Renata Dmowska, and Carlos Mendoza for their stimulating discussions and assistance during this project. Bob Engdahl and Eric Bergman provided exceptionally thorough reviews which lead to significant revision of the manuscript. This research was supported by grants to S.Y.S. from the Scott Turner Fund in the Department of Geological Sciences at the University of Michigan and Sigma Xi. S.Y.S. was supported by an AMOCO Ph.D Graduate Fellowship and the University of California President's Fellowship Program. T.L. was supported by NSF grant EAR-8451715. Contribution 64 of the Charles F. Richter Seismological Laboratory, University of California, Santa Cruz.

\section{REFERENCES}

Archuleta, R., A faulting model for the 1979 Imperial Valley earthquake, J. Geophys. Res., 89, 4559-4585, 1984.

Astiz, L., and H. Kanamori, Interplate coupling and temporal variation of mechanisms of intermediate depth earthquakes in Chile, Bull. Seismol. Soc. Am., 76, 1614-1622, 1986.

Beck, S. L., and L. J. Ruff, Rupture process of the great 1963 Kurile Islands earthquake sequence: Asperity interaction and multiple event rupture, J. Geophys. Res., 92, 14,123-14,138, 1987.

Boyd, T. M., and J. L. Nabelek, Rupture process of the Andreanof Islands earthquake of May 7, 1986, Bull: Seismol. Soc. Am., 78, $1653-1673,1988$.
Byrne, D. E., D. M. Davis, and L. R. Sykes, Loci and maximum size of thrust earthquakes and the mechanics of the shallow region of subduction zones, Tectonics, 7, 833-857, 1988.

Chatelain, J. L., B. L. Isacks, R. K. Cardwell, R. Prevot, and M. Bevis, Patterns of seismicity associated with asperities in the Central New Hebrides Island Arc, J. Geophys. Res., 91, 12,49712,519, 1986.

Chen, W.-P., and P. Molnar, Focal depths of intracontinental and intraplate earthquakes and their implications for the thermal and mechanical properties of the lithosphere, J. Geophys. Res., 88, 4183-4214, 1983.

Choy, G. L., and J. W. Dewey, Rupture process of an extended earthquake sequence: Teleseismic analysis of the Chilean earthquake of March 3, 1985, J. Geophys. Res., 93, 1103-1118, 1988.

Choy, G. L., and E. R. Engdahl, Analysis of broadband seismograms from selected IASPEI events, Phys. Earth Planet. Inter., $47,80-92,1987$.

Christensen, D. H., and L. J. Ruff, Outer-rise earthquakes and seismic coupling, Geophys. Res. Lett., 10, 697-700, 1983.

Christensen, D. H., and L. J. Ruff, Seismic coupling and outer rise earthquakes, J. Geophys. Res, 93, 13,421-13,444, 1988.

Das, S., and C. H. Scholz, Why large earthquakes do not nucleate at shallow depths, Nature, 305, 621-623, 1983.

Dewey, J. W., Seismicity and tectonics of western Venezuela, $B u l l$. Seismol. Soc. Am., 62, 1711-1751, 1972.

Dewey, J. W., Relocation of instrumentally recorded pre-1974 earthquakes from the South Carolina region, U.S. Geol. Surv. Prof. Pap., 1313, Q1-Q9, 1983.

Dewey, J. W., and D. W. Gordon, Map showing recomputed hypocenters of earthquakes in the eastern and central United States and adjacent Canada, 1925-1980, U.S. Geol. Surv. Misc. Field Map, MF-1699, 1 map and pamphlet, $39 \mathrm{pp} .1984$.

Dmowska, R., J. R. Rice, L. C. Lovison, and D. Josell, Stress transfer and seismic phenomena in coupled subduction zones during the earthquake cycle, J. Geophys. Res., 93, 7869-7884, 1988.

Dziewonski, A. M., and D. L. Anderson, Travel times and station corrections for $\boldsymbol{P}$ waves at teleseismic distances, J. Geophys. Res., 88, 3295-3314, 1983.

Dziewonski, A. M., A. Friedman, D. Giardini, and J. H. Woodhouse, Global seismicity of 1982: Centroid-moment tensor solutions for 308 earthquakes, Phys. Earth Planet. Inter., 33, 76-90, 1983. 
Dziewonski, A. M., G. Ekstrom, J. E. Franzen, and J. H. Woodhouse, Global seismicity of 1977: Centroid-moment tensor solutions for 471 earthquakes, Phys. Earth Planet. Inter., 45, 11-36, $1987 a$.

Dziewonski, A. M., G. Ekstrom, J. E. Franzen, and J. H. Woodhouse, Global seismicity of 1978: Centroid-moment tensor solutions for 512 earthquakes, Phys. Earth Planet. Inter., 46, 316-342, $1987 b$.

Dziewonski, A. M., G. Ekstrom, J. E. Franzen, and J. H. Woodhouse, Global seismicity of 1979: Centroid-moment tensor solutions for 524 earthquakes, Phys. Earth Planet. Inter., 48, 18-46, $1987 c$.

Dziewonski, A. M., G. Ekstrom, J. E. Franzen, and J. H. Woodhouse, Global seismicity of 1980: Centroid-moment tensor solutions for 515 earthquakes, Phys. Earth Planet. Inter., 50, 127-154, $1988 a$.

Dziewonski, A. M., G. Ekstrom, J. E. Franzen, and J. H. Woodhouse, Global seismicity of 1981: Centroid-moment tensor solutions for 542 earthquakes, Phys. Earth Planet. Inter., 50, 155-182, $1988 b$.

Engdahl, E. R., and S. Billington, Focal depth determination of Central Aleutian earthquakes, Bull. Seismol. Soc. Am., 76, 77-93, 1986.

Engdahl, E. R., J. W. Dewey, and K. Fujita, Earthquake location in island arcs, Phys. Earth Planet. Inter., 30, 145-156, 1982.

Evernden, J. F., Precision of epicenters obtained by small numbers of world-wide stations, Bull. Seismol. Soc. Am., 59, 1365-1398, 1969.

Fedotov, S. A., A. M. Bagdasarova, I. P. Kuzin, and R. Z. Tarakanov, Earthquakes and Deep Structure of the South Kurile Islands Arc, 249 pp., translated from Russian by Israel Program for Scientific Translations, Izdatel'stvo "Nauka", Moscow, 1969.

Flinn, E. A., Confidence regions and error determinations for seismic event location, Rev. Geophys., 3, 157-185, 1965.

Fukao, Y., Tsunami earthquakes and subduction processes near deep-sea trenches, J. Geophys. Res., 84, 2303-2314, 1979.

Hartzell, S. H., and T. H. Heaton, Inversion of strong groundmotion and teleseismic waveform data for the fault rupture history of the 1979 Imperial Valley, California, earthquake, Bull. Seismol. Soc. Am., 73, 1553-1583, 1983.

Hartzell, S. H., and T. H. Heaton, Rupture history of the 1984 Morgan Hill, California, earthquake from the inversion of strong ground-motion records, Bull. Seismol. Soc. Am., 76, 649-674, 1986.

Kanamori, H., The nature of seismicity patterns before major earthquakes, in Earthquake Prediction: An International Review, Maurice Ewing Ser., vol. 4, edited by D. W. Simpson and P. G. Richards, pp. 1-19, AGU, Washington, D.C., 1981.

Kawakatsu, H., and T. Seno, Triple seismic zone and the regional variation of seismicity along the northern Honshu arc, J. Geophys. Res., 88, 4215-4230, 1983.

Kikuchi, M., and Y. Fukao, Inversion of long-period $P$ waves from great earthquakes along subduction zones, Tectonophysics, 144, 231-247, 1987.

Langston, C., and D. Helmberger, A procedure for modelling shallow dislocation sources, Geophys. J. R. Astron. Soc., 42, 117-130, 1975.

Lay, T., L. Astiz, H. Kanamori, and D. Christensen, Temporal variation of large intraplate earthquakes in coupled subduction zones, Phys. Earth Planet. Inter., in press, 1988.

Mendoza, C., and S. Hartzell, Inversion for slip distribution using teleseismic $P$ waveforms: North Palm Springs, Borah Peak, and Michoacan earthquakes, Bull. Seismol. Soc. Am., 78, 1092-1111, $1988 a$.

Mendoza, C., and S. Hartzell, Aftershock patterns and mainshock faulting, Bull. Seismol. Soc. Am., 78, 1438-1449, $1988 b$.

Mori, J., and K. Shimazaki, Inversion of intermediate period Rayleigh waves for source characteristics of the 1968 Tokachi-Oki earthquake, J. Geophys. Res., 90, 11,374-11,382, 1985.

Olsen, A. H., and R. J. Apsel, Finite faults and inverse theory with application to the 1979 Imperial Valley earthquake, Bull. Seismol. Soc. Am., 72, 1969-2001, 1982.

Reyners, M., and K. S. Coles, Fine structure of the dipping seismic zone and subduction mechanics in the Shumagin Islands, Alaska, J. Geophys. Res., 87, 356-366, 1982.

Schwartz, S. Y., and L. J. Ruff, Asperity distribution and earthquake occurrence in the southern Kurile Islands Arc, Phys. Earth Planet. Inter., 49, 54-77, 1987.

Sibson, R. H., Roughness at the base of the seismogenic zone: Contributing factors, J. Geophys. Res., 89, 5791-5799, 1984.

Stauder, W., and L. Mualchin, Fault motion in the larger earthquakes of the Kurile-Kamchatka Arc and the Kurile-Hokkaido Corner, J. Geophys. Res., 81, 297-308, 1976.

Stein, S., and D. A. Wiens, Depth determination for shallow teleseismic earthquakes: Methods and results, Rev. Geophys., 24, 806-832, 1986.

Tse, S. T., and J. R. Rice, Crustal earthquake instability in relation to the depth variation of frictional slip properties, J. Geophys. Res., 91, 9452-9472, 1986.

van den Beukel, J., and R. Wortel, Temperatures and shear stresses in the upper part of a subduction zone, Geophys. Res. Lett., 14, 1057-1060, 1987.

Veith, K. F., The relationship of island arc seismicity to plate tectonics, Ph.D thesis, 69 pp., South. Methodist Univ., Dallas, Tex., 1974.

J. W. Dewey, U.S. Geological Survey, MS 967, Denver Federal Center, Box 25046 Denver, CO 80225.

T. Lay, Department of Geological Sciences, 1006 C.C. Little Bldg., University of Michigan, Ann Arbor, MI 48109.

S. Y. Schwartz, Charles F. Richter Seismological Laboratory, University of California, Santa Cruz, CA 95060.

(Received August 16, 1988; revised January 3, 1989; accepted January 3, 1989.) 